\title{
Destigmatizing Mental Illness in College Students
}

\author{
Ren VanderLind* \\ Texas State University, USA \\ Submission: May 04, 2017; Published: June 05, 2017 \\ *Corresponding author: Ren VanderLind, Texas State University, 600 University Drive, San Marcos, TX 78666, USA, Tel: 906 370-9282; \\ Email:1rv16@txstate.edu
}

\begin{abstract}
This article discusses the important issue of stigmatization among college students with mental illness, a population at risk for not attaining academic success. One factor that plays into this is the increasing numbers of college students reporting mental health concerns and lack of sufficient resources to serve their needs. This article is a call for action to work towards destigmatizing mental illness as a society in order to facilitate destigmatization on college campuses.
\end{abstract}

Keywords: Stigmatization; Mental illness; College students

\section{Destigmatizing Mental Illness in College Students}

College student mental health has been shown to relate to lack of academic success, persistence, and degree completion [1-6]. Because of these factors that make college students with mental illness at risk for lack of success and persistence, it is important for educators to understand the unique needs of this population.

Identity development in individuals with mental illness may require a restructuring of sense of self, something that may lead to self-stigmatization. Because college students are developing their academic and nonacademic identities during this formative period, it stands crucial to be able to provide supports to help the population of college students with mental illness as they forge their new sense of self, both as an individual with a mental illness and as a college student with a mental illness. Little research has examined how college students with mental illness develop positive identities, but some research points toward the issue of maladaptive perfectionism in women, which leads to poor mental health [7-12]. This way of conceiving of the self as needing to present perfectionism at all times has been shown to lead to poor mental health and increased stress in women who fail to meet their expectations. This may indicate a further need for understanding of self, self-compassion, and destigmatization of help-seeking behaviors.

There is clearly a need for destigmatization of mental illness, particularly on college campuses, where increasing numbers of students are reporting mental health concerns $[13,14]$. Popular media often depicts individuals with mental illness as violent people, which is not the case for the majority of this population; this most often occurs when individuals with mental illness go off their medications without doctor supervision. To destigmatize mental illness, then, there needs to be a socio cultural shift in how these individuals are viewed. Perhaps if the media portrayed a more sympathetic or empathetic picture of what it means to have a mental illness, the destigmatization process would begin, and college students with mental illness would be more apt to seek out academic and nonacademic supports to help them succeed.

This is a call for social justice for individuals with mental illness. Although they have invisible disabilities, they are nonetheless disabilities and should be treated as genuine medical concerns, not something to "just get over." Shifting social attitudes towards individuals with mental illness is crucial to helping college students with mental illness seek out the supports they need; students may be fearful of speaking to faculty or staff about their struggles and needs because of potentially negative perceptions and responses. If we are to effect change for these students and increase their likelihood of attaining academic success, we must first begin to change how we talk about issues of mental illness as a society.

\section{Reference}

1. Breslau N, Lane M, Sampson N, Kessler RC (2008) Mental health disorders and subsequent educational attainment in a US national sample. J Psychiatr Res 42(9): 708-716.

2. Cranford JA, Eisenberg D, Serras AM (2009) Substance use behaviors, mental health problems, and use of mental health services in a probability sample of college students. Addict Behav 34(2): 134-145. 
3. Elion AA, Wang KT, Slaney RB, French BH (2012) Perfectionism in African American students: Relationship to racial identity, GPA, selfesteem, and depression. Cultur Divers Ethnic Minor Psychol 18(2): 118-127.

4. Keyes CL, Eisenberg D, Perry GS, Dube SR, Kroenke K, et al. (2012) The relationship of level of positive mental health with current mental disorders in predicting suicidal behavior and academic impairment in college students. J Am Coll Health 60(2): 126-133.

5. Thompson EA, Connelly CD, Thomas-Jones D, Eggert LL (2013) School difficulties and co-occurring health risk factors: Substance use, aggression, depression, and suicidal behaviors. J Child and Adolesc Psychiatr Nurs 26(1): 74-84.

6. Novotney A (2014) Students under pressure. Monitor on Psychology 45(8): 37-41.

7. Abes ES, Jones SR, McEwen MK (2007/2011) Reconceptualizing the model of multiple dimensions of identity: The role of meaning-making capacity in the construction of multiple identities. In: Wilson ME (Ed.) ( $2^{\text {nd }}$ edn.), College student development theory, Boston, USA, pp. 85103

8. Castro JR, Rice KG (2003) Perfectionism and ethnicity: Implications for depressive symptoms and self-reported academic achievement. Cultur Divers Ethnic Minor Psychol 9(1): 64-78.
9. Gnilka PB, Ashby JS, Noble CM (2013) Adaptive and maladaptive perfectionism as mediators of adult attachment styles and depression, hopelessness, and life satisfaction. Journal of Counseling \& Development 91(1): 78-86.

10. Schrick BH, Sharp EA, Zvonkovic A, Reifman A (2012) Never let them see you sweat: Silencing and striving to appear perfect among U.S. college women. Sex Roles 67(11): 591-604.

11. Stoeber J, Schneider N, Hussain R, Matthews K (2014) Perfectionism and negative affect after repeated failure: Anxiety, depression, and anger. Journal of Individual Differences 35(2): 87-94.

12. Walker RL, Wingate LR, Obasi EM, Joiner TE (2008) An Empirical Investigation of Acculturative Stress and Ethnic Identity as Moderators for Depression and Suicidal Ideation in College Students. Cultur Divers Ethnic Minor Psychol 14(1): 75-82.

13. American College Health Association (2014) American College Health Association National College Health Assessment II spring 2014 reference group executive summary.

14. (2013) Center for Collegiate Mental Health. 